\title{
Validation of partial discharge emulator simulations using free- space radiometric measurements
}

\author{
Citation for published version: \\ Jaber, A, Lazaridis, P, Saeed, B, Zhang, Y, Khan, U, Upton, D, Ahmed, H, Mather, P, Vieira, MFQ, \\ Atkinson, R, Judd, M \& Glover, IA 2017, Validation of partial discharge emulator simulations using free- \\ space radiometric measurements. in 2016 International Conference for Students on Applied Engineering \\ (ICSAE)., 7810238, IEEE, 2016 International Conference for Students on Applied Engineering, 20/10/16. \\ https://doi.org/10.1109/ICSAE.2016.7810238
}

\section{Digital Object Identifier (DOI): \\ 10.1109/ICSAE.2016.7810238}

Link:

Link to publication record in Heriot-Watt Research Portal

Document Version:

Peer reviewed version

Published In:

2016 International Conference for Students on Applied Engineering (ICSAE)

Publisher Rights Statement:

(C) 2016 IEEE. Personal use of this material is permitted. Permission from IEEE must be obtained for all other uses, in any current or future media, including reprinting/republishing this material for advertising or promotional purposes, creating new collective works, for resale or redistribution to servers or lists, or reuse of any copyrighted component of this work in other works.

\section{General rights}

Copyright for the publications made accessible via Heriot-Watt Research Portal is retained by the author(s) and / or other copyright owners and it is a condition of accessing these publications that users recognise and abide by the legal requirements associated with these rights.

\section{Take down policy}

Heriot-Watt University has made every reasonable effort to ensure that the content in Heriot-Watt Research Portal complies with UK legislation. If you believe that the public display of this file breaches copyright please contact open.access@hw.ac.uk providing details, and we will remove access to the work immediately and investigate your claim. 


\title{
Validation of Partial Discharge Emulator Simulations using Free-Space Radiometric Measurements
}

\author{
A Jaber ${ }^{1}$, P Lazaridis ${ }^{1}$, B Saeed ${ }^{1}$, Y Zhang ${ }^{1}, \mathrm{U} \mathrm{Khan}^{1}, \mathrm{D} \mathrm{Upton}^{1}, \mathrm{H}_{\text {Ahmed }}{ }^{1}$, \\ P Mather $^{1}$, M F Q Vieira ${ }^{2}$, R Atkinson ${ }^{3}$, M Judd $^{4}$, and I A Glover ${ }^{1}$ \\ ${ }^{1}$ Department of Engineering \& Technology, University of Huddersfield, Huddersfield HD1 3DH, UK \\ ${ }^{2}$ Department of Electrical Engineering, Universidade Federal de Campina, Campina Grande, Brazil \\ ${ }^{3}$ Deptartment of Electronic and Electrical Engineering, University of Strathclyde, Glasgow G1 1XW, UK \\ 4High Frequency Diagnostics \& Engineering Ltd, Glasgow G2 6HJ, UK \\ E-mail: Adel.Jaber@hud.ac.uk
}

\begin{abstract}
A useful technique to estimate the degradation of insulation in high voltage (HV) installations is the measurement of partial discharge (PD). Free-space radiometric (FSR) detection of $P D$ is a relatively new technique. Several types of PD emulator sources have been constructed: two internal PD emulators and a floating electrode emulator. The emulators have been simulated using the CST Microwave Studio software package. The intention is to use the simulated emulators to establish a relationship between radiated $P D$ signals and $P D$ intensity as defined by apparent charge transfer. To this end the radiated fields predicted in the simulations are compared with measurements. There is sufficient agreement between simulations and measurements to suggest the simulations could be used to investigate the relationship between PD intensity and the field strength of radiated signals.
\end{abstract}

Keywords-CST Microwave Studio; Electromagnetic waves; FDTD; Free space radiometric measurement; Partial discharge

\section{INTRODUCTION}

Partial discharge (PD) is often a precursor event of high voltage (HV) equipment failure. PD diagnosis is an established means of verifying insulation condition. Any method to locate PD sources and assess their intensity would be a significant tool for the early detection of faulty $\mathrm{HV}$ equipment. Electromagnetic (EM) waves radiated from the PD source can be detected by sensors positioned near the HV equipment. The majority of energy in radiated PD signals lies in the very-high frequency (VHF) and ultra-high frequency (UHF) bands. The radiation of EM waves created by PD in HV apparatus therefore facilitates compromised insulation diagnosis and location $[1,2]$. The use of radiated PD signals is referred to as a free-space radiometric (FSR) method of PD detection and source location [3-6].

The design, validation and calibration of a FSR PD sensor network requires emulated PD sources, i.e. devices that radiate PD-like signals at stable, known, levels of intensity. Furthermore, if FSR measurements are to be used to infer the absolute intensity (in $\mathrm{pC}$ ) of $\mathrm{PD}$ processes then simulations in which both absolute PD intensity and radiated signal field strength can be simultaneously calculated will be enormously helpful. This paper models three PD sources and shows that they can be simulated successfully thus allowing future investigation of the radiated field strength versus absolute PD intensity relationship.

Validation of the simulations requires measurement of FSR PD signals from real PD sources (referred to here as PD emulators). The general measurement setup for a FSR measurement is shown in Figure 1.

Three PD emulators have been constructed. An emulator of the floating-electrode type and two internal PD emulators are depicted in Figure 2. The CST Microwave Studio software package, which can simulate transient electromagnetic fields using the FDTD (Finite Difference Time Domain) technique, has been used to model these emulators [7, 8].

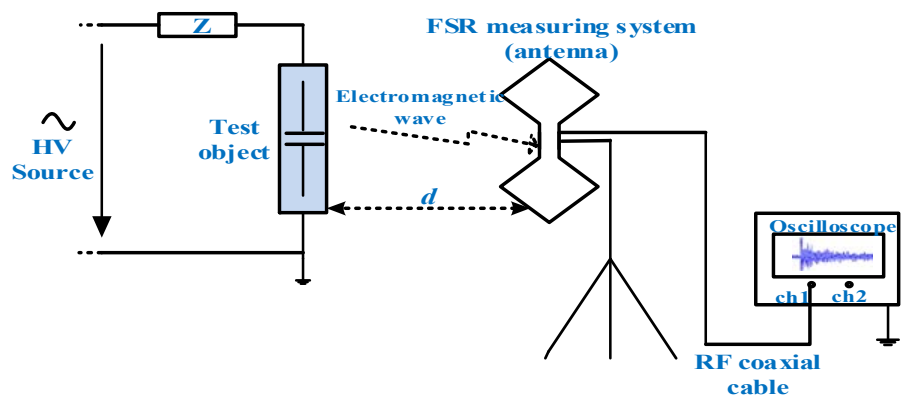

Fig. 1. Free-space radiometric PD measurement.

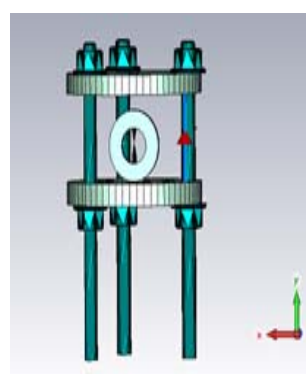

(a)

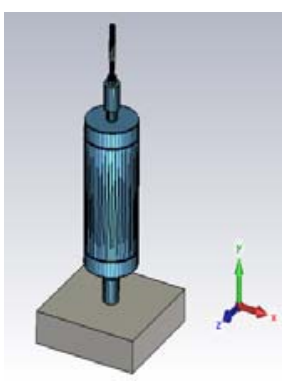

(b)

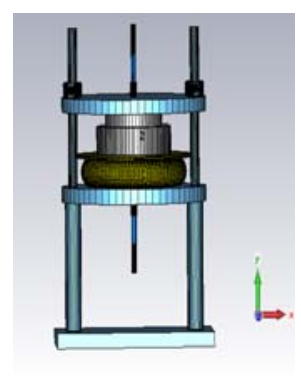

(c)
Fig. 2. PD emulator types: (a) floating-electrode (b) internal and (c) internal with epoxy dielectric.

To measure PD from the different emulators, the setup shown in Figure 3 is used. More information about PD measurement can be found in [9-11]. 


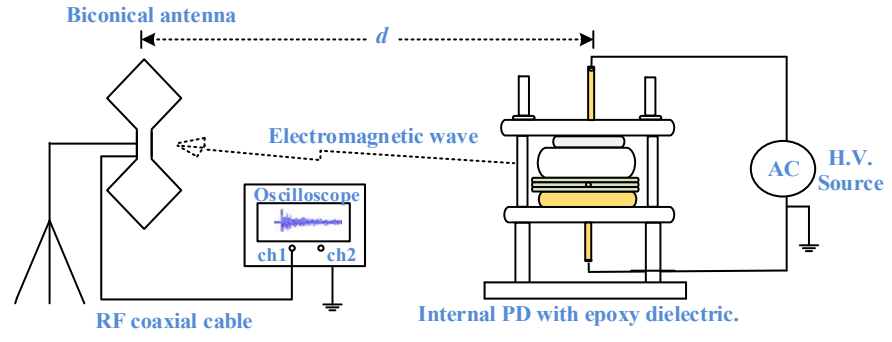

Fig. 3. PD measurement circuit with internal PD source.

$\mathrm{PD}$ is created by applying a $\mathrm{HV} 50 \mathrm{~Hz} \mathrm{AC}$ signal to three PD emulators. Measurements were performed using voltages of $15 \mathrm{kV}$ RMS for a floating-electrode PD emulator, $20 \mathrm{kV}$ RMS for an acrylic tube internal PD emulator and $18 \mathrm{kV}$ RMS for an internal epoxy dielectric PD emulator. The FSR measurements were made using a biconical antenna connected to a $20 \mathrm{GSa} / \mathrm{s}$ digital sampling oscilloscope (DSO) with an analog-bandwidth of $4 \mathrm{GHz}$. The biconical antenna, Figure 4, was located at a distance of $3 \mathrm{~m}$ from the PD source and was vertically polarised.

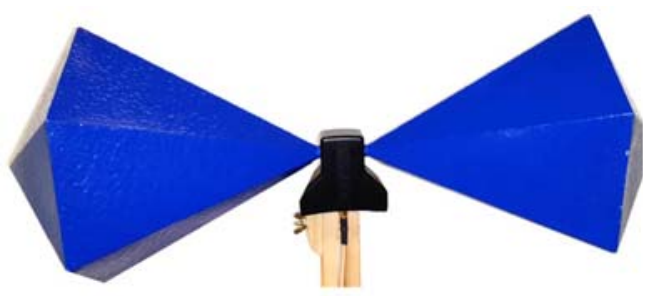

Fig. 4. Biconical antenna

The frequency range of the antenna is $20 \mathrm{MHz}$ to $1 \mathrm{GHz}$ and its nominal impedance is $50 \mathrm{ohms}$. The antenna gain at $100 \mathrm{MHz}$ is around $-9 \mathrm{dBi}$ and its dimensions are $540 \mathrm{~mm} \times 225 \mathrm{~mm}$ $\times 225 \mathrm{~mm}$.

The floating-electrode PD emulator is shown in Figure 5. The output of the HV power supply is connected to the lower electrode, and the upper electrode is connected to earth. When the electric field is sufficiently large a discharge is initiated from the floating electrode $[12,13]$.

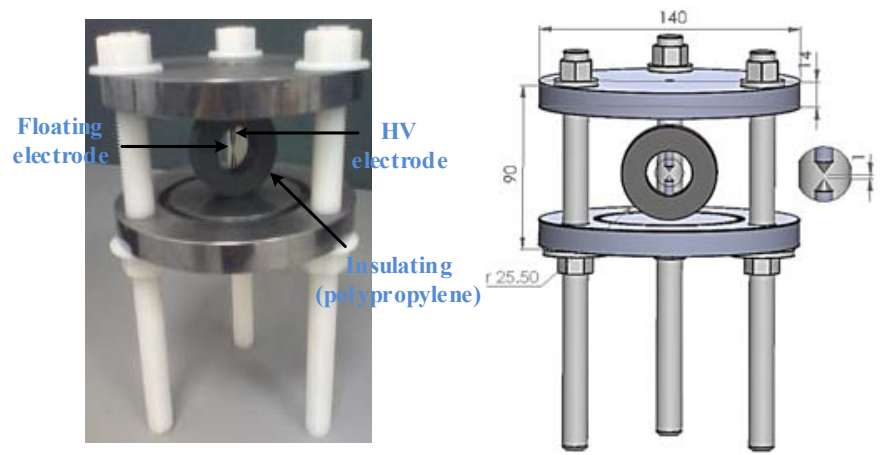

Fig. 5. Floating electrode PD emulator (dimensions in $\mathrm{mm}$ ).

An internal PD source is shown in Figure 6. The electrodes are smaller than those in the floating electrode emulator. The insulation is perspex. The edges of the electrodes are rounded to avoid the enhanced electrical field strength, and the resulting corona, that would otherwise occur close to the sharp edge [14]. The insulator was constructed by compressing three circular plates between the two electrodes to form a composite disc. The thickness of each plate is $1.5 \mathrm{~mm}$. The insulation defect necessary for the occurrence of partial discharge is realised by drilling a hole (diameter $1 \mathrm{~mm}$ ) in the middle plate [14]. The electrodes and insulating disc are enclosed in an acrylic cylinder filled with transformer oil to avoid discharge from the disc edges.

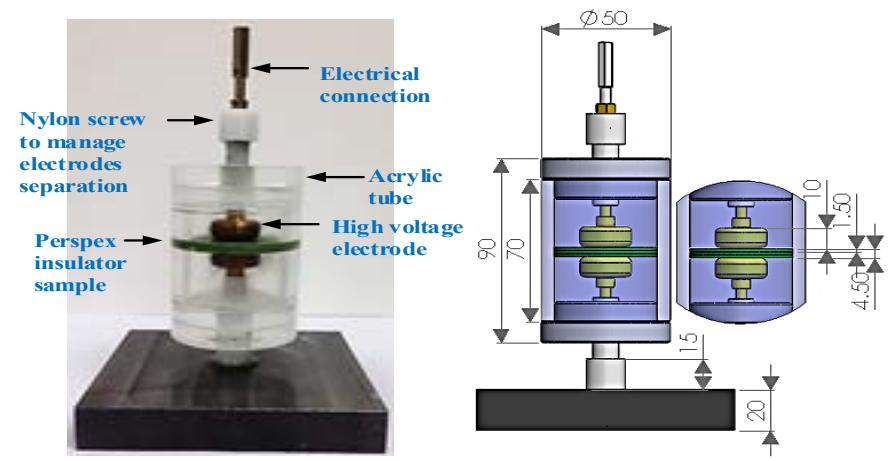

Fig. 6. Acrylic tube internal PD emulator (dimensions in $\mathrm{mm}$ ).

A second internal PD emulator is shown in Figure 7. The insulation comprises three epoxy glass plates. A cavity with a diameter of $1 \mathrm{~mm}$ was drilled in the middle plate. The thickness of the three-plate composite is $2.4 \mathrm{~mm}$. The HV electrode is made from stainless steel with a well-rounded edge to avoid surface discharge from regions of elevated field strength $\lceil 15\rceil$.

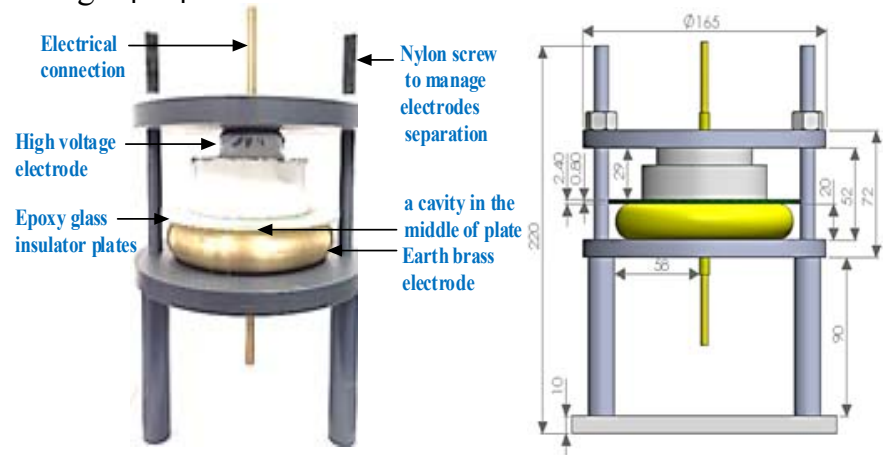

Fig. 7. Epoxy dielectric internal PD emulator (dimensions in $\mathrm{mm}$ ).

\section{FSR PD MEASUREMENTS AND SIMULATIONS}

Measurements were made of the radiated PD signals from all three emulators. In each case the sensing antenna was located $3 \mathrm{~m}$ from the emulator. The received signals are shown in Figure 8.

A Gaussian current signal with a frequency spectrum in the VHF-UHF band has been used to excite in the simulated PD sources. The Gaussian signal is $[7,16]$ :

$i(t)=I_{0} e^{\left(\frac{-\left(t-t_{0}\right)^{2}}{2 \sigma^{2}}\right.}$

where $\mathrm{I}_{0}$ is the peak current, $\sigma$ characterizes the pulse width and $t_{0}$ is the time the pulse peaks. The charge contained within the pulse (at least approximately equal to the apparent charge of the PD intensity) is:

$q=I_{0} \sigma \sqrt{2 \pi}$ 

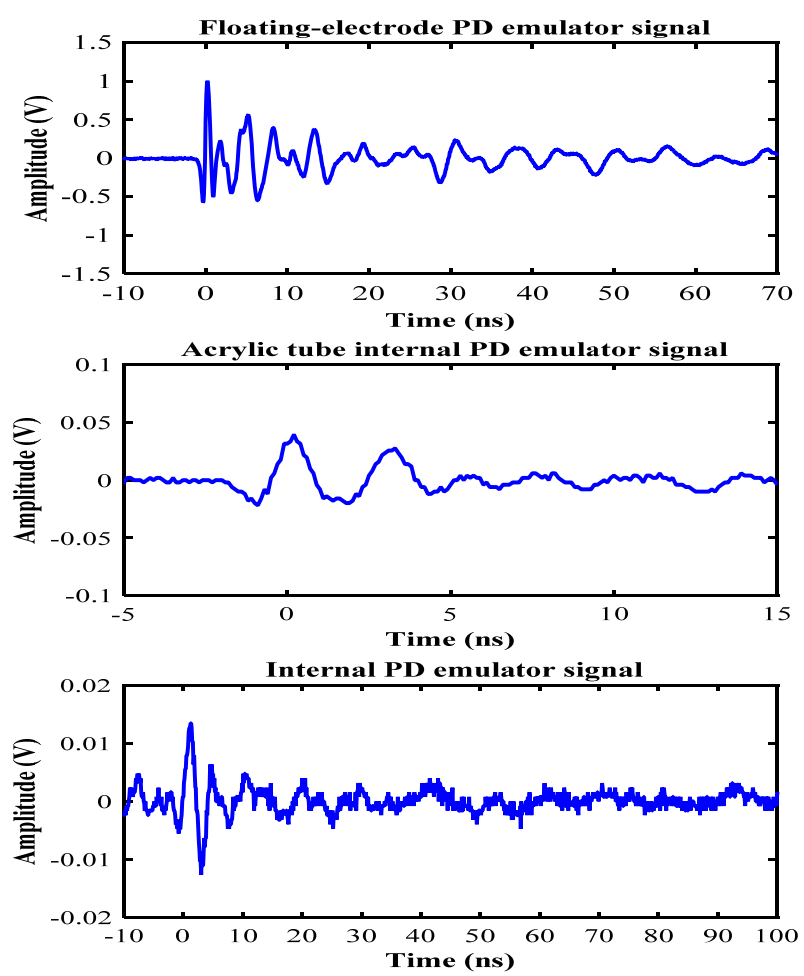

Fig. 8. PD FSR measurement signals.

The radiated electric fields predicted by simulation at a distance of $3 \mathrm{~m}$ for each of the emulators in response to excitation by the above current pulse are shown in Figure 9. Simulated and measured fields are compared in Figure 10. The CST simulation of the PD emulators are in good agreement with the measurements. This gives confidence in the simulations which may, therefore, be used to calculate absolute PD intensity (in $\mathrm{pC}$ ) and relate this to radiated signal field strength at a particular distance from the PD source.
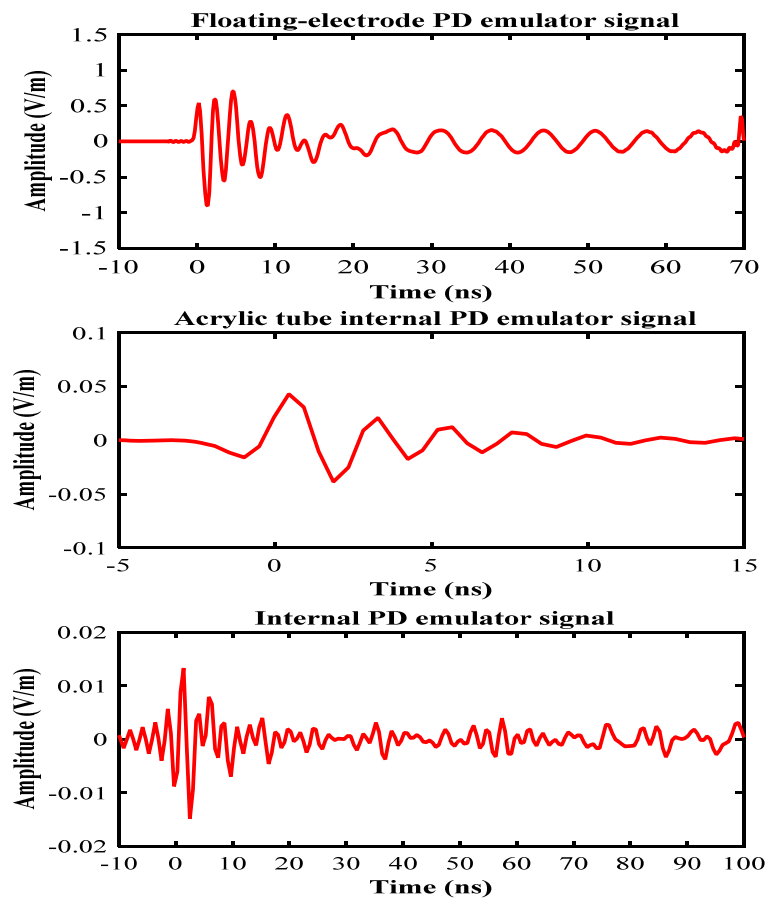

Fig. 9. Simulated PD electrical fields.
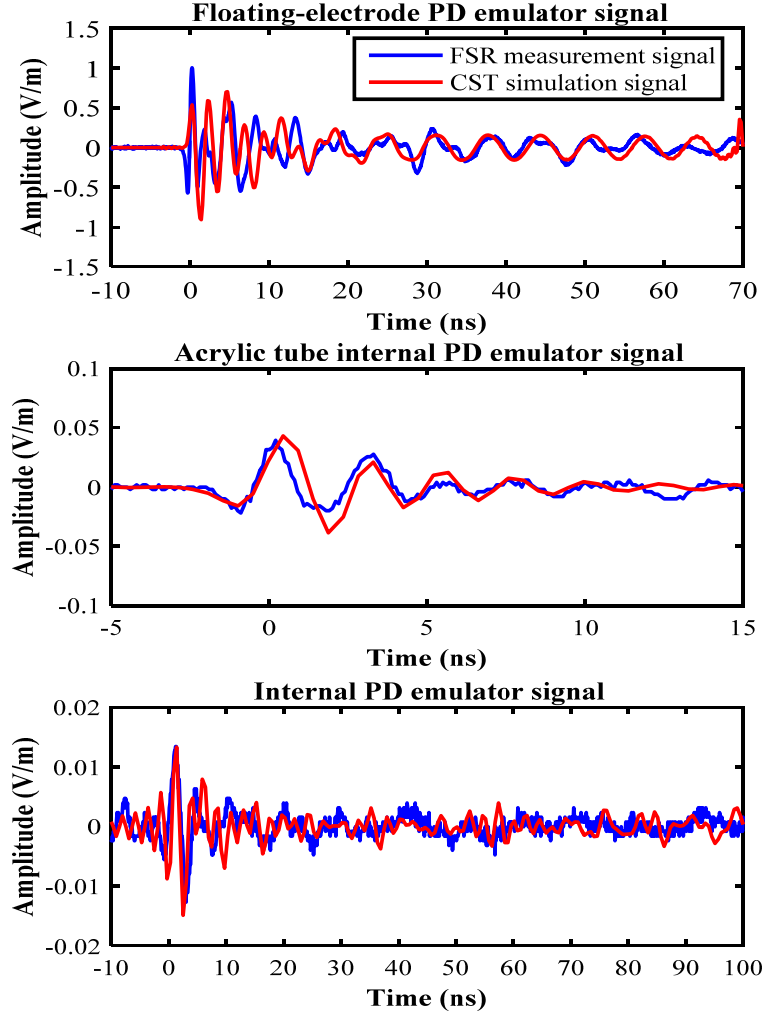

Fig. 10. Comparison of measured and simulated PD electrical field amplitudes.

\section{CONCLUSIONS}

Three different PD emulators have been constructed and the radiated fields from each due to a given excitation derived by simulation. The PD intensity corresponding to the excitation is easily calculated allowing this to be related to radiate PD field strength. The simulations have been validated by measuring the radiated fields, comparing them with the fields predicted from simulation and showing the agreement to be good. The validated simulations will be used to investigate the relationship between FSR PD measurements and absolute PD intensity. If such a relationship can be, even approximately, established then the utility of FSR PD measurement and locations systems for the condition monitoring of insulation integrity in high voltage plant will be greatly enhanced.

\section{ACKNOWLEDGMENT}

The authors acknowledge the Engineering and Physical Sciences Research Council for their support of this work under grant EP/J015873/1.

\section{REFERENCES}

[1] Y. Zhang, D. Upton, A. Jaber, H. Ahmed, B. Saeed, P. Mather, P. Lazaridis, A. Mopty, C. Tachtatzis, R. Atkinson, M. Judd, M F Q Vieira, and I A Glover, "Radiometric wireless sensor network monitoring of partial discharge sources in electrical substations," International Journal of Distributed Sensor Networks, vol. 2015, p. 179, 2015.

[2] Y. Zhang, D. Upton, A. Jaber, H. Ahmed, U. Khan, B. Saeed, P. Mather, P. Lazaridis, R. Atkinson, M.F. Q Vieira, I.A. Glover, "Multiple Source Localization for Partial Discharge Monitoring in Electrical Substation," ," in Antennas \& Propagation Conference (LAPC), Loughborough, 2015, pp. 1-4. 
[3] Y. Zhang, J. M. Neto, D. Upton, A. Jaber, U. Khan, B. Saeed, P. Mather, P. Lazaridis, R. Atkinson, M.F. Q Vieira, I.A. Glover, "Radiometer monitoring system for partial discharge detection in substation," in Radio Science Conference (URSI AT-RASC), 2015 1st URSI Atlantic, 2015, pp. 1-1.

[4] J. M. Neto, Y. Zhang, A. Jaber, M. Zhu, M. Judd, R. Atkinson, J. Soraghan, J.S. Neto, M.F. Q Vieira, and I A Glover, "Radiometric location of partial discharge sources for the future smart grid," in General Assembly and Scientific Symposium (URSI GASS), XXXIth URSI, Beijing, 2014, pp. 1-4.

[5] I. E. Portugues, P. J. Moore, I. A. Glover, C. Johnstone, R. H. McKosky, M. B. Goff, et al., "RF-Based Partial Discharge Early Warning System for Air-Insulated Substations," IEEE Transactions on Power Delivery, vol. 24, pp. 20-29, 2009.

[6] P. J. Moore, I. E. Portugues, and I. A. Glover, "Radiometric location of partial discharge sources on energized high-Voltage plant," IEEE Transactions on Power Delivery, vol. 20, pp. 2264-2272, 2005.

[7] M. Zanjani, A. Akbari, N. Shirdel, E. Gockenbach, and H. Borsi, "Investigating partial discharge UHF electromagnetic waves propagation in transformers using FDTD technique and 3D simulation," in Condition Monitoring and Diagnosis (CMD), 2012 International Conference, Bali, Indonesia, 2012, pp. 497-500.

[8] S. Fernando, W. Rowe, and K. Wong, "Partial discharge detection using antenna like activity of overhead distribution cables," in Universities Power Engineering Conference (AUPEC), 2010 20th Australasian, 2010, pp. 1-5.

[9] A. Jaber, P. Lazaridis, B. Saeed, Y. Zhang, U. Khan, D. Upton, H. Ahmed, P. Mather, M. F. Q Vieira, R Atkinson, M. Judd, and I. A. Glover, "Assessment of Absolute Partial Discharge Intensity from a Free-space Radiometric Measurement," 2016 URSI Asia- Pacific Radio Science Conference (URSI AT-RASC), Seoul, Korea, 2016, pp. 1-4.

[10] A. Jaber, P. Lazaridis, B. Saeed, Y. Zhang, U. Khan, D. Upton, H. Ahmed, P. Mather, M. F. Q Vieira, R Atkinson, M. Judd, and I. A.
Glover, "Comparative study of Partial Discharge Emulators for the Calibration of Free-Space Radiometric Measurements," 22nd IEEE International Conference on Automation and Computing (ICAC'16), Colchester, UK, 2016, pp. 1-4.

[11] A. Jaber, P. Lazaridis, B. Saeed, Y. Zhang, U. Khan, D. Upton, H. Ahmed, P. Mather, M. F. Q Vieira, R Atkinson, M. Judd, and I. A. Glover,, "Frequency Spectrum Analysis of Radiated Partial Discharge Signals," IET EUROEM 2016 conference (European Electromagnetics Symposium), London, UK, 2016, pp. 1-2.

[12] B. Hampton, "UHF diagnostics for gas insulated substations," in High Voltage Engineering, 1999. Eleventh International Symposium on (Conf. Publ. No. 467), 1999, pp. 6-16.

[13] A. Jaber, P. Lazaridis, B. Saeed, Y. Zhang, U. Khan, D. Upton, H. Ahmed, P. Mather, M. F. Q Vieira, R Atkinson, M. Judd, and I. A. Glover, "Comparison of contact measurement and free-space radiation measurement of partial discharge signals," in Automation and Computing (ICAC), 2015 21st International Conference on, 2015, pp. 14

[14] J. de Souza Neto, E. de Macedo, J. da Rocha Neto, E. Da Costa, S. Bhatti, and I. Glover, "Partial Discharge Location using Unsynchronized Radiometer Network for Condition Monitoring in HV Substations-A Proposed Approach," in Journal of Physics: Conference Series, 2012, p. 012053.

[15] M. G. Niasar, N. Taylor, P. Janus, X. Wang, H. Edin, and R. C. Kiiza, "Partial discharges in a cavity embedded in oil-impregnated paper: effect of electrical and thermal aging," IEEE Transactions on Dielectrics and Electrical Insulation, vol. 22, pp. 1071-1079, 2015.

[16] H. Karami, G. Gharehpetian, and M. Hejazi, "Oil Permittivity Effect on PD Source Allocation Through Three-dimensional Simulation," 28 International power system conference, Tehran-Iran, 2013, pp. 1-5. 